\title{
Short Term Electric Load Forecasting of Kathmandu Valley of Nepal using Artificial Neural Network
}

\author{
Binod Bhandari*, Shree Raj Shakya, Ajay Kumar Jha \\ Department of Mechanical Engineering, Institute of Engineering, Tribhuvan University \\ Corresponding Email: "bhbinod51@gmail.com
}

\begin{abstract}
Decision making in the energy sector has to be based on accurate forecasts of the load demand. Short-term forecasting, which forms the focus of this paper, gives a day ahead hourly forecast of electric load. This forecast can help to make important decisions in the field of scheduling, contingency analysis, load flow analysis, preventing imbalance in the power generation and load demand, load switching strategies, thus leading to greater network reliability and power quality. A method called Artificial Neural Network is used to anticipate the future load of Kathmandu Valley of Nepal. The Neural Network is build, trained with historical data along with seven different input variables and used for prediction of day ahead 24 hours load. The output is validated with the real Load collected from NEA. In addition, forecasting is performed by some other time series methods as well, and whose output are compared with that of neural network. The range of Mean Absolute Deviation for four different time series models lied between 1.50-2.59. When the errors were calculated in terms of MSE and MAPE the range of these values were found to be in between 2.59-7.78, and 1.615.07 respectively. The Artificial Neural Network proved to be the more accurate forecast method when the results are compared in terms of error measurements with a MAD having 1.23, MSE having 1.79 and MAPE having 1.17. The Neural Network proved to be more accurate method comparatively with satisfactory minimum error.
\end{abstract}

\section{INTRODUCTION}

$\mathrm{D}^{\mathrm{s}}$ ECISION making in the field of power generation, transmission, distribution and proper operation has to be based on accurate forecasts of the load demand [1]. Forecasts of electric load on different time spans are needed for the operation of power plants and energy markets as well. Several decision problems are observed in the field of power system and energy markets which should be solved on the basis of accurate anticipation of future load. These problems includes balancing the power generation and consumption, determination of an optimal load scheduling, proper unit commitment of power plants, efficient day to day operation of power system network, procurement of energy by electric utilities in energy markets and energy allocation. Thus decisions are based on two aspects. One is day to day operation of power system and other is investment decision relying on the anticipation of future energy demands. For both ends, reliable forecasts are needed [2].

To participate in the market, a player needs an accurate estimate how much energy is needed at a certain time. Load forecasting is therefore at the core of nearly all decisions made in energy markets.

Accurate models for electric power load forecasting are essential to the operation and planning of a utility company [3]. Load forecasting helps an electric utility to make important decisions including decisions on purchasing and generating electric power, load switching, and infrastructure development. Load forecasts are equally important for energy suppliers, financial institutions, and other participants in electric energy generation, transmission, distribution, and markets.

Types of load forecasts can be divided into various categories that include short-term forecasts, medium-term forecasts, and long-term forecasts [4].Short-term forecasting which forms the focus of this paper, gives a forecast of electric load for time span of one hour to one week period. Such forecast can help to make decisions aimed at preventing imbalance in the power generation and load demand, thus leading to greater network reliability and power quality [5].

Many methods have been used for load forecasting in the past. These include statistical methods such as regression and similar-day approach, fuzzy logic, expert systems, support Vector machines, econometric models, end-use models, etc. [6].

Although many attempts have been done to forecast load using several methods around the world, neural network method is not being used for electrical load prediction in context of Nepal. In addition, the forecasting has been done in Nepal by Government owned Utility Nepal Electricity Authority (NEA) [7]. However, this is done for long term purpose only. Almost no attempts have been done for short term load forecasting in context of Nepal.

Although Neural Network method is being used to predict in several sectors, however for prediction of electric load in Nepal, it is unattempt. Since the Kathmandu Valley uses about significant percentage of total Power Generated in Nepal, and is the capital city, many plans should be done for this region based on energy anticipation. Thus an attempt has been done for developing a model and forecasting the future load of the Kathmandu Valley using the method called Neural Network. Likewise four other time series models were incorporated for forecasting and compared with the output of ANN.

A supervised artificial neural network is used in this work in more depth. Here, the neural network is trained with two years of historical input data by considering the load affecting factors like temperature, time of day, day of week and holidays/events. The trained network is able to make predictions based on the relationships learned during training. In order to check whether the forecasted load resembles the accurate one, validation is done by comparing the forecasted load with real data. 


\section{Basics Of ANN}

Artificial neural networks are mathematical tools originally inspired by the way the human brain processes information. Their basic unit is the artificial neuron, schematically represented in Fig.1. The neuron receives (numerical) information through a number of input nodes, processes it internally, and puts out a response. Signals that arrive to the node are the neuron's inputs and can be whether attenuated or amplified by means of an associated weight. These input signals can excite the neuron if positive weighted synapses are carried out or, on the contrary, they can inhibit it if the weight is negative. Finally, if the sum of the weighted inputs is equal or greater than a certain threshold, the neuron is activated [8].

In a general term its structure can be understood from the Figure 2. The common type of artificial neural network consists of three groups, or layers, of units: a layer of "input" units is connected to a layer of "hidden" units, which is connected to a layer of "output" units. The weights between the input and hidden units determine when each hidden unit is active, and so by modifying these weights, a hidden unit can choose what it represent [5].

Deciding the number of neurons in the hidden layers is a very important part of deciding the overall neural network architecture. Though these layers do not directly interact with the external environment, they have a tremendous influence on the final output. Both the number of hidden layers and the number of neurons in each of these hidden layers must be carefully considered.

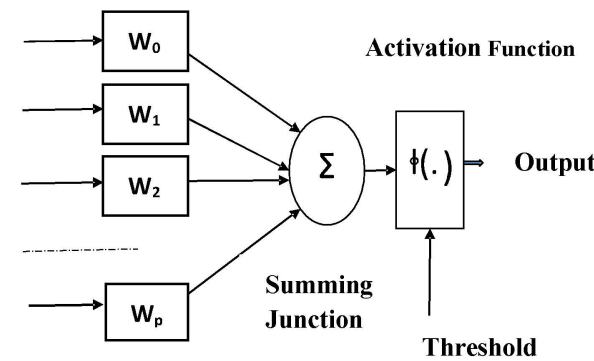

Input Synaptic Weights

Fig.1. Mathematical model of ANN

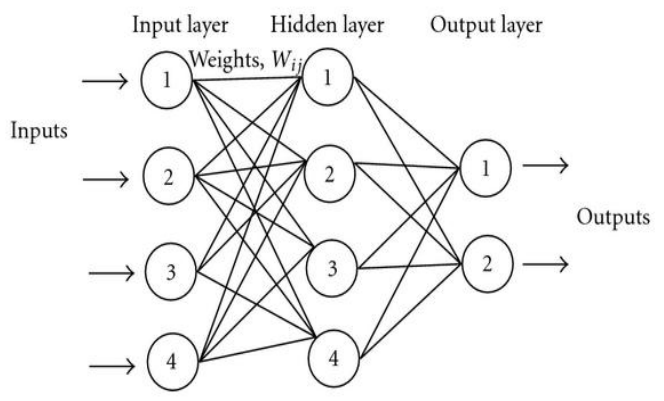

Fig. 2 Basic Structure of ANN

Feed-forward neural networks allow signals to flow through the network in one direction only: from input to output. Data enter the neural network through the input units on the left. The output values of the units are modulated by the connection weights. The most widely used learning method in feed-forward networks is the back-propagation of error. Back-propagation is a form of supervised learning in which the network's connections are adjusted to minimize the error between the actual and the correct output. In backpropagation, the input data are repeatedly presented to the neural network. The output of the neural network is compared to the desired output and an error is computed. This error is then fed back (back-propagated) to the neural network and used to adjust the weights such that the error decreases with each iteration until it achieves an acceptable value (gradient descent) and the neural model gets closer and closer to producing the desired output. This process is known as "training", [9].

With reference to the number of layers, ANN can be classified into monolayer or multilayer networks (MLP). The first ones only have one input layer and one output layer, whereas the multilayer networks are generalization of the monolayer ones, which add intermediate or hidden layers between the input and the output [10]. When discussing about the connection type, the ANN can be feedforward if the signal propagation is produced in just one way and, therefore, they do not have a memory or recurrent if they keep feedback links between neurons in different layers, neurons in the same layer or in the same neuron. Finally, the connection grade can be totally connected if all neurons in a layer are connected with the neurons in the next layer (feedforward networks) or with the neurons in the last layer (recurrent networks) and, otherwise, partially connected networks in cases where there is not total connection among neurons from different layers.

Learning paradigm: The learning is a process that consists in modifying the weights of the ANN, according to the input information. The changes that can be carried out during the learning process are removing (the weight is set to zero), adding (conversion of a weight equal to zero to a weight different to zero) or modifying neurons connections. The learning process is said to be finished or, in other words, the network has learnt when the values assigned to the weights remain unchanged [10].

\section{Methodology OF ANN}

The basic flow chart of methodology used for this work is shown in Fig. 3.

This begins with the collection of Historical Load data. Thus collected hourly load data are pre-processed to analyze the past load curve, trends and seasons. Furthermore factors that would affect those loads were identified in parallel. Then those data are divided into two sets training sets and test sets. A neural network is build and trained with those preprocessed historical load with the different factors taken into account. Then the load is forecasted for the test date. Different error parameters are calculated in order to check the forecast accuracy. If the accuracy is accepted then by using the same trained neural network the new forecast is done for desired time horizon. And if the accuracy is not 
acceptable certain neural network adjustment is done. For this number of inputs, number of training days and number of hidden layers neurons used to build the network were modified until the accuracy is acceptable.

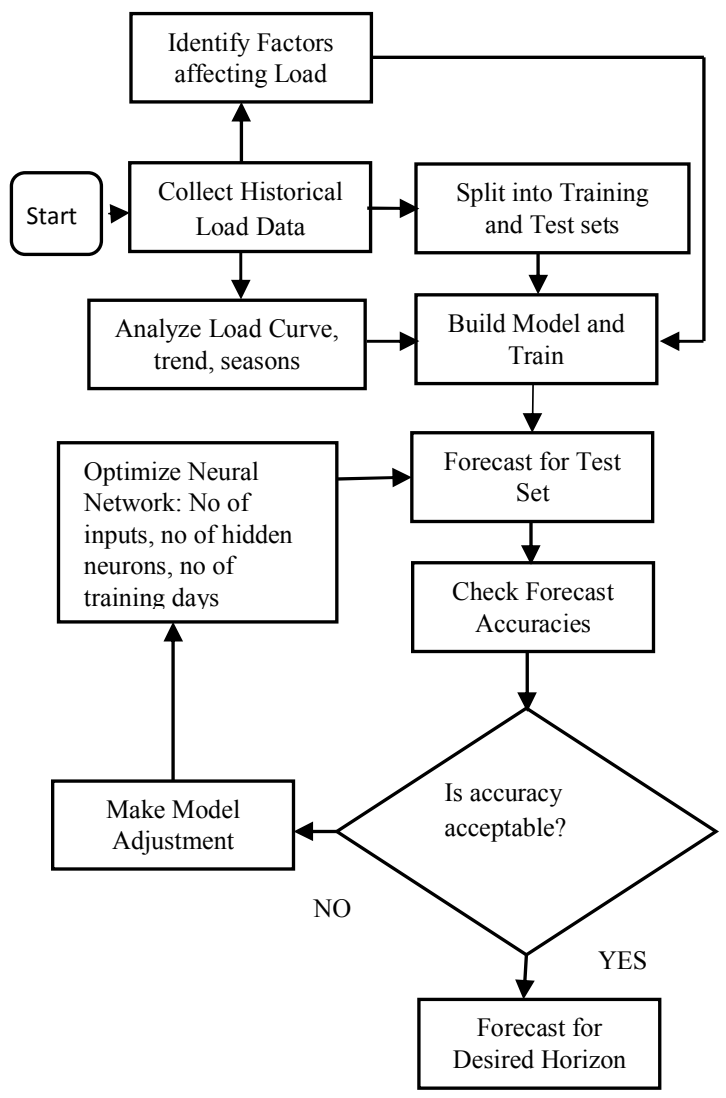

Fig. 3. Forecasting Methodology

The electricity load of selected site, Kathmandu valley depends on many factors. After analyzing the historical load data and corresponding load curves, factors affecting the load were identified. There were seven predictor variables used as inputs to the input layer of the network shown in Fig. 4. They are:

- Temperature

- Hour of a day

- Day of the week

- A Flag indicating if it is holidays/weekdays

- Previous day's average load

- Load from the same hour the previous day

- Load from the same hour and same day from previous week.

In order to simulate the neural network algorithm these data are separated into two parts: training set (used for training the network) and Test set (for validation with real data) that was not used in the training process of the neural network. Past three years 2071 B.S. to 2073 B.S. (Corresponding $2014 / 4 / 14$ to $2017 / 04 / 13$ A.D.) Data were taken as training set. And a day 2017/04/14 was taken as validation purpose. The methodology for the purposed system in broad term includes data collection, pre-processing of data, Network development and Training, Forecasting and validating.

\section{A. Data Collection}

For the research purpose various data are required .This research concerns with the electrical load demand by the particular concerned region (Kathmandu) and various constraints like time, weather, and others.

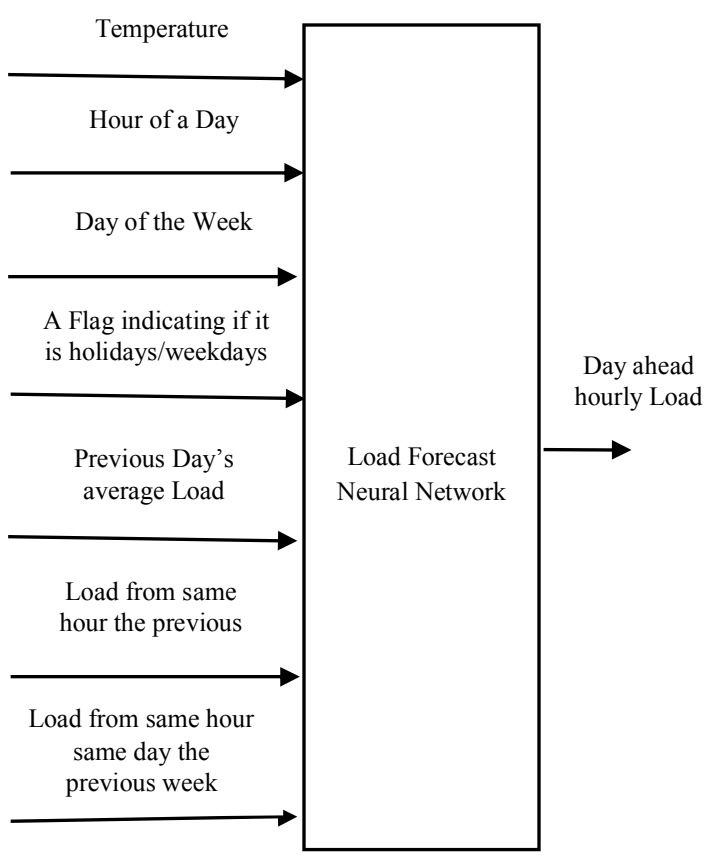

Fig. 4. Schematic Model

In order to process the past historical data, the three years electrical load data was collected from Load Dispatch Centre, Nepal Electricity Authority. Likewise the corresponding weather data was collected from Department of Hydrology and Meteorology, Government of Nepal. The time frame of data collection is shown in Table I.

TABLE I

Data used for Simulation

\begin{tabular}{|c|c|c|}
\hline $\begin{array}{c}\text { Collected } \\
\text { Data }\end{array}$ & Daily Average Load & Daily Temperature \\
\hline Training & $2014 / 04 / 14$ to & $2014 / 04 / 14$ to \\
\hline Period & $2017 / 04 / 13$ & $2017 / 04 / 13$ \\
\hline $\begin{array}{l}\text { Validation } \\
\text { Period }\end{array}$ & 2017/04/14 & $2017 / 04 / 14$ \\
\hline Source & $\begin{array}{c}\text { Nepal Electricity } \\
\text { Authority, Government } \\
\text { of Nepal }\end{array}$ & $\begin{array}{c}\text { Department of Hydrology } \\
\text { and Meteorology, } \\
\text { Government of Nepal. }\end{array}$ \\
\hline
\end{tabular}

\section{B. Pre Processing of Data}

After the collection of data, the collected data were reconstructed to make compatible for input in the model. There were some missing values in the data which were adjusted by necessary interpolation and comparing with the concerned information without affecting the trend of actual data. For the purpose of modeling first MS. Excel tools is taken into consideration for initial sorting. Since the raw data taken from the two sources are almost random the preprocessing of those data is very necessary. The Neural Network seeks the historical load data and corresponding 
temperatures in its own format, hence the collected data was processed accordingly before feeding into the model. The respective data is then entered into appropriate software for further analysis process.

\section{Network Development and Training}

A network is developed and it is trained with the historical data along with the factors consideration. For this purpose, the neural network created has three layers- input, hidden and output. The inputs to the neural network are the multiplied by the weights and acted upon by the transfer or activation function. The output which is the Forecasted hourly load data is obtained from the output layer. The network chosen for the purpose of this work is the Multilayer-Layer perceptron (MLP).There were seven predictor variables used as inputs to the input layer of the network as shown in Fig. 4.

The days of the week were assigned numerical values from 1-7 from Sunday to Saturday. The time of the day in hours were also assigned numbers from 1-24 representing lam to 12 midnight. The dates were converted into numeric representation using appropriate formula for their unique identification to call when necessary in the coding. The overall predictor matrix was created by considering all input variables temperature, hour, weekday, working days, previous day's average load, previous day same hour load and previous week same day same hour load Comprising in each column. The forecast model was then designed and trained using the MATLAB software R2013b. Adjustments were now made to the network till the best performance was achieved. To get the best network, the number of epochs, hidden layers, activation functions, and the network architecture and so on can be adjusted. Likewise, this model was trained with levenberg-marquardt algorithm which is particularly used to solve nonlinear least squares problems. The model with the best performance had twenty neurons in the hidden layer and one neuron in the output layer. The sigmoid transfer function was used as the activation function. The neural network architecture used for this forecast is showing Table II and its block diagram is shown in Fig. 5.

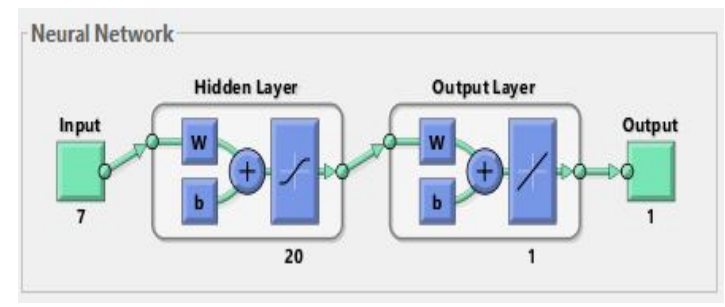

Fig. 5. Neural Network Configuration

\section{Forecasting and Validation}

Next, the day ahead load for a week is forecasted by using the network developed for year 2074 B.S. The results (the forecasted loads) were compared with real data of same period provided by NEA. In order to evaluate the performance of the network model validating techniques like Mean Square Error (RMS) Root Mean Square Error
(RMSE), Mean Absolute percentage Error (MAPE) and Mean Average Deviation (MAD) were used.

TABLE II

Neural Network Architecture

\begin{tabular}{ccccc}
\hline \hline $\begin{array}{c}\text { Number } \\
\text { of Inputs }\end{array}$ & $\begin{array}{c}\text { Number of } \\
\text { Hidden layers } \\
\text { Neurons }\end{array}$ & $\begin{array}{c}\text { Number of } \\
\text { output } \\
\text { Neuron }\end{array}$ & $\begin{array}{c}\text { Activation } \\
\text { Function }\end{array}$ \\
\hline 7 & 20 & & 1 & Sigmoid \\
\hline \hline
\end{tabular}

\section{RESULT AND DISCUSSION}

The result of the simulation is the day ahead hourly load. This forecasted load obtained after running the model for day 2017/04/14 is mentioned in the Table III. Also, in order to check whether the forecasted load were near to the real load the Actual Load for the same time provided by NEA is put on the same table in next column.

TABLE III

Forecasted ANAD actual hourly load

\begin{tabular}{|c|c|c|}
\hline $\begin{array}{l}\text { Time } \\
\text { (Hour) }\end{array}$ & $\begin{array}{c}\text { Forecasted Load } \\
(\text { MW) }\end{array}$ & $\begin{array}{l}\text { Actual Load } \\
\text { (MW) }\end{array}$ \\
\hline 1 & 104.84 & 105.55 \\
\hline 2 & 102.00 & 102.78 \\
\hline 3 & 101.42 & 101.99 \\
\hline 4 & 101.12 & 101.79 \\
\hline 5 & 106.98 & 107.73 \\
\hline 6 & 152.74 & 153.97 \\
\hline 7 & 151.07 & 152.32 \\
\hline 8 & 146.03 & 147.37 \\
\hline 9 & 143.05 & 144.06 \\
\hline 10 & 139.87 & 140.76 \\
\hline 11 & 141.18 & 142.41 \\
\hline 12 & 128.89 & 129.20 \\
\hline 13 & 126.75 & 127.88 \\
\hline 14 & 125.66 & 126.73 \\
\hline 15 & 129.28 & 130.52 \\
\hline 16 & 129.09 & 130.85 \\
\hline 17 & 136.83 & 137.46 \\
\hline 18 & 227.68 & 229.94 \\
\hline 19 & 229.67 & 231.59 \\
\hline 20 & 214.62 & 216.73 \\
\hline 21 & 175.46 & 177.09 \\
\hline 22 & 163.56 & 165.53 \\
\hline 23 & 109.98 & 111.70 \\
\hline 24 & 104.35 & 105.75 \\
\hline
\end{tabular}

Table III shows the forecasted loads in Mega Watts of each hour for targeted day. We can see that the forecasted Peak load was found to be $231.59 \mathrm{MW}$ at $7 \mathrm{PM}$ evening. This Peak load was observed at the same hour to that of actual load, the deviation being $1.196 \mathrm{MW}$. It is observed that the forecasted loads at different hours deviated with some errors however, most of them being less than $1 \mathrm{MW}$.

The corresponding Forecasted Load Curve for same day is plotted in Fig. 6. It was observed in the Fig. 6 that the load curve of forecasted load follows the same nature to that of actual load. It was also seen that there was deviation of loads from few $\mathrm{kW}$ to $1.97 \mathrm{MW}$. However, in most of the hours the deviation was found to be less than $1 \mathrm{MW}$. 


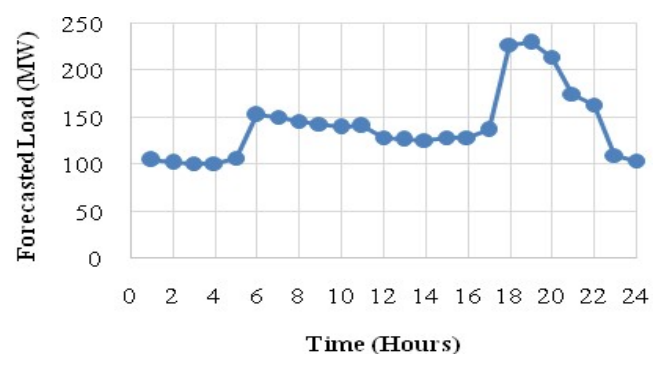

Fig. 6. Forecasted Load Curve

In order to calculate these deviation in overall, different error parameters like Mean Absolute Deviation (MAD), Mean Square Error (MSE), root mean square error (RMSE), Mean Absolute Percentage Error (MAPE) and were calculated and are mentioned in Table III.

\begin{tabular}{c|c|c|c}
\multicolumn{4}{c}{$\begin{array}{c}\text { TABLE III } \\
\text { Error parameter }\end{array}$} \\
\hline \hline MAD $^{\mathbf{a}}$ & $\mathbf{M S E}^{\mathbf{b}}$ & $\mathbf{R M S E}^{\mathbf{c}}$ & MAPE $^{\mathbf{d}}$ \\
\hline 1.23 & 1.79 & 1.34 & 1.17 \\
\hline \hline
\end{tabular}

The performance statistics of validation phase are presented in Table III. The Mean Absolute Deviation was found to be 1.23. The Mean Square Error and Root Mean Square Error was found to be 1.79 and 1.34 respectively. Likewise the Mean Absolute Percentage Error was found to be 1.17.In overall, these statistical error parameter values need to compare with other time series method.

\section{COMPARISON With OTHER TIME SERIES MOdELS}

TABLE IV

Comparison among different models

\begin{tabular}{|c|c|c|c|c|c|c|}
\hline $\begin{array}{l}\text { Time } \\
\text { (Hrs) }\end{array}$ & $\begin{array}{c}\mathbf{M A}^{\mathbf{a}} \\
(\mathbf{M W})\end{array}$ & $\begin{array}{l}\text { WMA }^{\mathbf{b}} \\
\text { (MW) }\end{array}$ & $\begin{array}{c}\mathbf{E S}^{\mathbf{c}} \\
(\mathbf{M W})\end{array}$ & $\begin{array}{l}\text { HW }^{\mathrm{d}} \\
\text { (MW) }\end{array}$ & $\begin{array}{l}\mathbf{A N N}^{\mathrm{e}} \\
(\mathrm{MW})\end{array}$ & $\begin{array}{l}\text { Actual } \\
\text { (MW) }\end{array}$ \\
\hline 1 & 104.09 & 104.65 & 104.61 & 103.40 & 104.84 & 105.55 \\
\hline 2 & 101.38 & 100.96 & 101.88 & 99.25 & 102.00 & 102.78 \\
\hline 3 & 100.61 & 100.19 & 101.10 & 98.06 & 101.42 & 101.99 \\
\hline 4 & 100.41 & 102.00 & 100.90 & 98.26 & 101.12 & 101.79 \\
\hline 5 & 106.22 & 105.76 & 106.76 & 104.93 & 106.98 & 107.73 \\
\hline 6 & 151.38 & 152.59 & 152.30 & 151.26 & 152.74 & 153.97 \\
\hline 7 & 149.77 & 148.99 & 150.67 & 151.50 & 151.07 & 152.32 \\
\hline 8 & 143.93 & 145.19 & 145.79 & 148.31 & 146.03 & 147.37 \\
\hline 9 & 141.70 & 140.99 & 142.54 & 146.16 & 143.05 & 144.06 \\
\hline 10 & 138.48 & 137.79 & 139.28 & 143.36 & 139.87 & 140.76 \\
\hline 11 & 140.09 & 139.39 & 140.91 & 144.85 & 141.18 & 142.41 \\
\hline 12 & 127.19 & 126.58 & 127.90 & 131.50 & 128.89 & 129.20 \\
\hline 13 & 125.90 & 125.30 & 126.60 & 129.40 & 126.75 & 127.88 \\
\hline 14 & 124.77 & 124.18 & 125.46 & 127.39 & 125.66 & 126.73 \\
\hline 15 & 128.48 & 127.86 & 129.20 & 130.33 & 129.28 & 130.52 \\
\hline 16 & 128.80 & 128.18 & 129.53 & 130.13 & 129.09 & 130.85 \\
\hline 17 & 135.25 & 134.58 & 136.03 & 136.31 & 136.83 & 137.46 \\
\hline 18 & 225.57 & 226.25 & 227.11 & 226.78 & 227.68 & 229.94 \\
\hline 19 & 227.18 & 228.85 & 228.74 & 230.15 & 229.67 & 231.59 \\
\hline 20 & 212.66 & 211.44 & 214.10 & 217.53 & 214.62 & 216.73 \\
\hline 21 & 173.96 & 173.01 & 175.07 & 180.00 & 175.46 & 177.09 \\
\hline 22 & 162.67 & 161.80 & 163.68 & 168.57 & 163.56 & 165.53 \\
\hline 23 & 110.09 & 109.61 & 110.66 & 115.02 & 109.98 & 111.70 \\
\hline 24 & 104.29 & 103.84 & 104.80 & 107.19 & 104.35 & 105.75 \\
\hline
\end{tabular}

${ }^{\mathrm{a}} \mathrm{MA}=$ Moving Average, ${ }^{\mathrm{b}} \mathrm{WMA}=$ Weighted Moving Average, ${ }^{\mathrm{c}} \mathrm{ES}=$ Exponential Smoothing, ${ }^{\mathrm{d}} \mathrm{HW}=$ Holt's Winter, ${ }^{\mathrm{e}} \mathrm{ANN}=$ Artificial Neural Network
Apart from the Artificial Neural Network, forecasting were carried out with other time series models in order to compare their accuracies with neural network output. The time series models that were used for prediction of short term electric load of Kathmandu Valley are Moving Average, Weighted Moving Average, Exponential Smoothing and Holt's winter's method. The forecasted Loads for the same day from all the models are presented in Table IV.

For Moving Average, average of earlier week same hour load was considered so as to get optimum result.

In case of Weightage Moving Average, the more weightage is given for the day nearer to the forecasting day. In Exponential Smoothing model, the value of smoothing constant alpha was optimized first so as to minimize the Mean Square Error. Then the optimum value of alpha, turned out to be 0.722 was used in the basic equation of exponential smoothing. In other technique, called Holts Winter's Exponential method, the values of level, trend and seasonal constant alpha, beta and theta were optimized with excel solver so as to minimize the mean square error. Then these optimum values of alpha, beta and theta were used in model to predict the following day hourly load. Likewise different error parameters were calculated for each time series methods which are presented in Table V.

TABLE IV

Accuracy comparison among different models

\begin{tabular}{ccccc}
\hline \hline Models & ${ }^{\mathrm{a}}$ MAD & ${ }^{\mathrm{b}}$ MSE & ${ }^{\mathrm{c}} \mathbf{R M S E}$ & ${ }^{\mathrm{d}}$ MAPE \\
\hline Moving Average & 2.37 & 6.43 & 2.54 & 4.01 \\
Weighted Moving & 2.59 & 7.78 & 2.79 & 5.07 \\
$\quad \begin{array}{c}\text { Average } \\
\text { Exponential }\end{array}$ & 1.50 & 2.59 & 1.61 & 1.61 \\
$\begin{array}{c}\text { Smoothing } \\
\text { Holt's Winters } \\
\text { Method }\end{array}$ & 2.09 & 5.51 & 2.35 & 4.35 \\
ANN & 1.23 & 1.79 & 1.34 & 1.17 \\
\hline \hline
\end{tabular}

\section{CONCLUSIONS}

Thus, the model was created in Artificial Neural Network, trained with large set of data by considering different factors that affect the short term electric load of Kathmandu Valley. The trained network forecasted day ahead hourly load of Kathmandu valley, which was validated with real load. In addition, forecasting was done with other four time series models whose error parameters were compared with Neural Network method. The Artificial Neural Network proved to be the best forecast method when the results are compared in terms of error measurements with a MAD having 1.23, MSE having 1.79 and MAPE having 1.17. While the range of MAD, MSE, RMSE and MAPE lied between 1.50-2.59, 2.59-7.78,1.61-2.79,1.61-5.07 respectively for other methods. The Artificial neural network (ANN) model was the best of all the methods showing the robustness of the method to model non-linear load data.

\section{ACKNOWLEDGEMENTS}

The authors would like to thank Nepal Electricity Authority, Government of Nepal for providing necessary data of 
historical load for Kathmandu Valley and Department of Hydrology and Meteorology, Government of Nepal for providing essential historical data of temperature. Also, authors would like to express warm gratitude to Engineer Sushil Paudel, Load Dispatch Centre for his valuable suggestions throughout the work. We thank Mrs. Tara Pandey Bhandari for assisting in this research work that greatly improved the manuscript.

\section{REFERENCES}

[1] E. Almeshaiei and H. Soltan, "A Methedology for Electric Power Load Forecasting ", Alexandria Engineering Journal, (2011)

[2] D.Asber, S.Lefebvre, J.Asber,M.Saad, C. Desbiens. "Nonparametric short-term load forecasting". International Journal of Electrical Power and Energy Systems, (October 2007).

[3] Alfares.K.H, Nazeeruddin.M. "Electric load forecasting: literature survey and classification of methods". International Journal of Systems Science, (2002).

[4] G.A. Adepoju,S.O.A. Ogunjuyigbe, and K.O. Alawode, "Application of Neural Network to Load Forecasting in Nigerian Electrical Power System”, Pacific Journal of Science and Technology,(2007)

[5] N. Patel, R. Patel and A. Gupta, "Advanced Neural Network Applied In Engineering Science", International Journal of Engineering Sciences \& Research Technology, (2014)

[6] Load Forecast Report(2014/15): Nepal Electricity Authority

[7] A.J. Al-Shareef, E.A. Mohamed and E.Al-Judaibi, "Next 24Hours Load Forecasting Using Artificial Neural Network (ANN) for the Western Area of Saudi Arabia", Journal of King Abdullaz University, (2008)

[8] Bhattacharyya,S. C, Le T. Thanh. "Short-Term Electric Load Forecasting Using An Artificial Neural Network: Case Of Northern Vietanm". International Journal of Energy (2004).

[9] C. M. Bishop, "Neural networks for pattern recognition", Oxford: Claredon Press; (1997)

[10] Canbing Li, Meiping Fu, Jincheng Shang, Peng Cheng. "A novel probabilistic short-term load forecasting method for large power grid". Power and Energy Engineering Conference (APPEEC), Asia Pacific, (2010)

[11] Luis Hernandez, Carlos Baladr ' on, Javier M Aguiar, Bel' enCarro, Antonio J Sanchez-Esguevillas, and Jaime Lloret. Short-term load forecasting for micro grids based on artificial neural networks. Energies, 6(3):1385-1408, (2013)

[12] Tao Hong. Short term electric load forecasting. Phd thesis, North Carolina State University, (2010)

[13] Nathaniel Charlton and Colin Singleton. A refined parametric model for short term load forecasting. International Journal of Forecasting, 30(2):364-368,( 2014)

[14] I. Samuel, T. Ojewola, A. Awelewa, P. Amaize, "Short Term Forecasting Using Time Series and Artificial Neural Network Methods". Journal of Electrical and Electronics EngineeringISSN: 2278-1676, p-ISSN: 2320-3331, Volume 11, Issue 1 Ver. III PP 72-81,(Jan. - Feb. 2016),

[15] T.K. Chheepa, T. Mangalaini, "A Critical Review on Employed Techniques for Short Term Load Forecasting "International Research Journal of Engineering and Technology (IRJET) Volume: 04 Issue: 06, (June-2017)

[16] K. Srivastava, A. Pandey and Devender Singh, "Short-Term Load Forecasting Methods: A Review" International Conference on Emerging Trends in Electrical, Electronics and Sustainable Energy Systems (ICETEESES-16), (2016)

[17] J. W. Taylor and P. E. McSharry, "Short-Term Load Forecasting Methods: An Evaluation Based on European Data" IEEE Transactions on Power Systems, (2008)

\section{BIOGRAPHIES}

Binod Bhandari is an Electrical engineer. He received Bachelor's Degree in Electrical Engineering from Pulchowk Campus, Institute of Engineering, Tribhuvan University, Nepal. He is graduate student of Master of Science in Renewable Energy Engineering in same Institution. At present, he is working as a full time lecturer in the Department of Electrical Engineering at Kathmandu Engineering College, Kathmandu. He has published few papers in national journals related to electrical engineering. $\mathrm{He}$ is also the founder chairman of non-government organization Nexus UNESCO Club.His research interests lie in the area of Renewable Energy Engineering, Power System and Social Science.

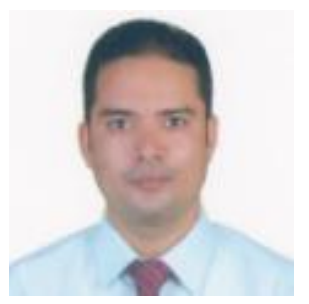

Shree Raj Shakya is Director of Center for Energy Studies and coordinator of MS in Energy System Planning and Management, Institute of Engineering, Tribhuvan University, Nepal. He has received $\mathrm{PhD}$ Degree in Energy Engineering from Asian Institute of Technology, Thailand. He completed M.Sc. in Renewable Energy Engineering from Institute of Engineering, Pulchowk Campus. He has published more than 30 papers in different international and national peerreviewed journals. His fields of research are energy systems modeling, analysis and planning, energy and climate change policies, low carbon and sustainable development, green growth and renewable energy technologies.

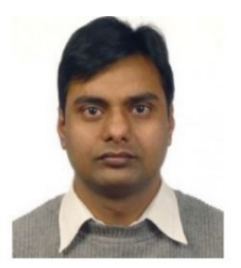

Ajay Kumar Jha is coordinator of M.Sc. in Renewable Energy Engineering, Institute of Engineering, Pulchowk Campus. He has received his $\mathrm{PhD}$ degree in Environmental Science and Engineering from Harbin Institute of Engineering, China. He completed M.Sc. in Renewable Energy Engineering and Bachelors in Mechanical Engineering from Institute of Engineering, Pulchowk Campus. He has published more than forty research papers in national and international journals. His fields of research are Renewable Energy, Solar PV Technologies, Biogas Technology. 